\title{
Multicentric breast cancer with heterogeneous histopathology: a multidisciplinary review
}

\author{
Giovanni Corso* ${ }^{* \ddagger 1,2}$ (D) , Francesca Magnoni ${ }^{\ddagger, 2}$ (D), Elena Provenzano ${ }^{3}$, Antonia Girardi², \\ Monica lorfida ${ }^{4}$, Alessandra Margherita De Scalzi ${ }^{2}$, Alessandra Invento ${ }^{2}$, Marco Colleoni ${ }^{4}$, \\ Enrico Cassano ${ }^{5}$, Chiara Trentin ${ }^{5}$, Roberto Lo Gullo ${ }^{5}$, Gabriella Pravettoni ${ }^{1,6}$, Laura Gilardi ${ }^{7}$, \\ Chiara Maria Grana ${ }^{7}$, Mattia Intra ${ }^{2}$, Viviana Galimberti ${ }^{2}$, Paolo Veronesi ${ }^{1,2}$, Francesca De \\ Lorenzi $^{8} \&$ Maria Cristina Leonardi ${ }^{9}$ \\ ${ }^{1}$ Faculty of Medicine, University of Milan, Milan, Italy \\ ${ }^{2}$ Division of Breast Surgery, European Institute of Oncology, IRCCS, Milan, Italy \\ ${ }^{3}$ NIHR Cambridge Biomedical Research Centre, Cambridge University Hospitals NHS Foundation Trust, Cambridge, UK \\ ${ }^{4}$ Division of Medical Senology, European Institute of Oncology, IRCCS, Milan, Italy \\ ${ }^{5}$ Division of Breast Imaging, European Institute of Oncology, IRCCS, Milan, Italy \\ ${ }^{6}$ Applied Research Division for Cognitive \& Psychological Science, European Institute of Oncology, IRCCS, Milan, Italy \\ ${ }^{7}$ Division of Nuclear Medicine, European Institute of Oncology, IRCCS, Milan, Italy \\ ${ }^{8}$ Division of Plastic \& Reconstructive Surgery, European Institute of Oncology, IRCCS, Milan, Italy \\ ${ }^{9}$ Division of Radiation Oncology, European Institute of Oncology, IRCCS, Milan, Italy \\ *Author for correspondence: Tel.: +39 0294375 161; giovanni.corso@ieo.it \\ $\ddagger$ Authors contributed equally
}

Multiple synchronous (multifocal or multicentric) ipsilateral breast cancers with heterogeneous histopathology are a rare clinical occurrence, however, their incidence is increasing due to the use of MRI for breast cancer screening and staging. Some studies have demonstrated poorer clinical outcomes for this pattern of breast cancer, but there is no evidence to guide clinical practice. In this multidisciplinary review, we reflect on pathology and molecular characteristics, imaging findings, surgical management including conservation and reconstructive options and approach to the axilla, and the role of chemotherapy and radiotherapy. Multidisciplinary discussions appear decisive in planning an appropriate surgical choice and defining the correct systemic treatment tailored to each clinical condition.

First draft submitted: 4 September 2019; Accepted for publication: 21 January 2020; Published online: 6 February 2020

Keywords: breast cancer $\bullet$ breast cancer histotypes $\bullet$ diagnosis $\bullet$ lobular carcinoma $\bullet$ multicentric cancer $\bullet$ multidisciplinary team • multifocal cancer $\bullet$ prognosis $\bullet$ surgical management

Multiple synchronous (multifocal or multicentric) ipsilateral breast cancers (MSIBC) with heterogeneous histopathology represent a rare clinical conundrum. Breast cancer $(\mathrm{BC})$ is now defined not only by histological but by molecular characteristics reflected in the new TNM prognostic staging [1], so tumors with different morphological and molecular profiles in the same patient introduce challenges in therapeutic decision-making. Clear treatment guidelines for this difficult subset of $\mathrm{BC}$ are not described in the literature due to the low clinical frequency.

One of the key decisions in this group of patients regards medical therapy, and whether to deliver this in the adjuvant or neoadjuvant setting. $\mathrm{BC}$ adjuvant therapies are defined in accordance with estrogen receptor (ER), progesterone receptor ( $\mathrm{PgR})$ and HER2 status; endocrine therapy is indicated for ER and PgR-positive BC, chemotherapy is classically recommended for triple-negative $\mathrm{BC}$ with a move toward platinum-based regimes, and HER2-positive tumors receive HER2-targeted agents in conjunction with chemotherapy. In the case of heterogeneous $\mathrm{BC}$, the nature and timing of medical therapy is extremely important to facilitate surgical downstaging, avoid breast recurrence and improve prognosis.

Future Medicine 
There is often discussion regarding the optimal breast surgical approach and whether breast conservation surgery (BCS) rather than mastectomy is appropriate. When the tumor affects breasts bilaterally, patients are often treated with mastectomy, with BCS having an as yet unclear role [2]. There is no significant difference in survival for patients with bilateral BC compared with unilateral tumors [3], however, synchronous tumors are associated with poorer survival in comparison to metachronous tumors [2]. In this multidisciplinary review, we propose a clinical management for MSIBC with heterogeneous histopathology.

\section{Tumor heterogeneity \& cancer genetics}

Historically, MSIBC were defined as multicentric when they occurred in different quadrants and multifocal when they were in the same quadrant; due to inconsistencies in defining these terms and their lack of functional anatomical relevance, this has been replaced with the term 'multiple BCs' $[4,5]$. In histological terms, BC is defined as multiple when it consists of more than one well distinguished tumor foci separated by normal or benign breast tissue or by intervening Ductal Carcinoma In Situ (DCIS) [6]. The American Joint Committee Cancer (AJCC) tumor node metastasis (TNM) staging system defines tumor size as the size of the single largest focus of MSIBC [5].

Some authors support the hypothesis that MSIBC tumors are best represented by the aggregate dimension that reclassifies tumors to a more advanced stage [7]. In the literature, the incidence of MSIBC varies from $6-77 \%$, and is dependent upon both use of imaging modalities such as MRI and the thoroughness of histological sampling [4,6]. In patients affected by T1-T2N0-1 BC, MSIBC were found in 21\% of mastectomy specimen in a study from the MD Anderson Cancer Center [8]. There are two main theories as to how multiple tumor foci arise in the same breast that are not mutually exclusive: they represent local in breast metastasis arising from a single primary lesion, or they have arisen independently and represent true separate primary lesions. It can be challenging using standard morphological characteristics alone to determine which cases represent true synchronous primary tumors and which are in breast metastases originating from a single primary.

Histologic $\mathrm{BC}$ classification is performed in accord with the morphologic heterogeneity of BC. Invasive ductal cancer (IDC or no special type) is the most common histologic type of invasive BC (40-75\%) [9]. Moreover, there are 21 special subtypes of BC defined by the WHO in 2012, and invasive lobular cancer (ILC) is the most frequent $(15 \%)$. The other BC special subtypes are rarely diagnosed and with great differences in relation to prognosis and response to adjuvant treatment [10-13]. Papillary, mucinous and tubular carcinomas usually show the best outcomes, instead metaplastic carcinoma and poorly differentiated IDC have worse prognosis that often require more aggressive systemic treatments [14]. Several series looking at MSIBC have been published in the literature; in $5-37 \%$ of cases the tumor deposits are of different histological subtypes, and in 6-30\% the foci are of different grade $[6,15-17]$.

In terms of biomarker expression, ER is discordant in $2-12 \%$ of cases, PgR in $11-19 \%$ and HER2 is different in $2-16 \%[6,15-20]$. Looking at combined receptor expression to give molecular subtype, this was discordant in $6-13 \%$ of cases $[6,15,17]$. Differences in ER and HER2 expression are often associated with differences in tumor morphology, however, Buggi et al. specifically looked at tumors with similar histology and found ER was discordant in $4 \%$ and HER 2 in $10 \%$, resulting in a change in therapy in $12 \%$ of patients [21]. Gene expression profiling is now used in predicting benefit from chemotherapy, particularly in ER-positive HER2-negative disease. One series found a difference in the Oncotype $D \times 21$ gene recurrence score (RS) in 4/18 ipsilateral tumor foci that would have resulted in a difference in recommendation for chemotherapy [22].

In patients with concordant scores tumor histology and grade differed in 18.8 and $6.3 \%$ of cases, respectively, as compared with 66.7 and $50 \%$ of cases for those with discordant scores ( $\mathrm{p}=0.05$ and 0.04 for tumor histology and grade, respectively). Although not statistically significant, tumors with different RS were also more likely to differ in PgR status (33.3 vs 18.8\%). Patients with accordant scores presented tumor histology and grade different in 18.8 and $6.3 \%$ of cases, respectively, as compared with 66.7 and $50 \%$ of cases for those with discordant scores ( $\mathrm{p}=0.05$ and 0.04 for tumor histology and grade, respectively). PgR status appeared likely different in tumors with unlike RS (33.3 vs 18.8\%), although without statistical significance. This is clinically important, as current AJCC guidelines recommend testing of the largest focus only unless the smaller foci are of different grade or histological subtype [1]. A more recent retrospective trial demonstrated that RS were discordant in 33\% of women with ERpositive, HER2-negative, node-negative, synchronous bilateral invasive BC, leading to a change in treatment in $57 \%$ of these patients. Discordance in RS was demonstrated in a more recent retrospective trial demonstrated that RS were discordant in 33\% of women with ER-positive, HER2-negative, node-negative, synchronous bilateral invasive $\mathrm{BC}$, causing a change in treatment in $57 \%$ of these patients. There is far less in the literature looking at the 
underlying genetic differences in multiple synchronous breast cancers. Biermann et al. found that four of eleven cases of synchronous ipsilateral breast cancers were of different intrinsic subtype; one of these was also of different histological subtype with IDC and lobular foci [23].

The authors also undertook molecular analyses using array-based comparative genomic hybridization, methylation, gene expression and RNA sequencing and found 4/11 cases were independent and 7/11 were of clonal origin; interestingly three quarters of cases were independent on both clinical and molecular characteristics, while one case was discordant histologically but showed similar molecular features, while another was discordant on molecular but not histological characteristics.

While being of different subtype is a clear indicator of separate synchronous primary tumors, as over $70 \%$ of invasive BCs are classified as IDC having the same morphology does not conversely mean that tumors are clonally related. Desmedt $e t$ al. looked at a series of 36 patients with multiple invasive ductal carcinomas with the same grade and hormone receptor (HR) status using a targeted sequencing approach, and found roughly a third of cases had the same mutation profile, a third had shared mutations indicating common clonal origin but also had private mutations in different foci, and a third had no shared mutations [24]. The tumors without any common mutations were situated further apart than those with shared driver mutations, although the difference did not reach statistical significance. Of note, despite there being no shared mutations, shared copy number changes were found between lesions suggesting deeper interrogation with tools such as whole-genome sequencing may find evidence of shared subclones with clonal divergence in a greater proportion of cases. One series examining tumoral heterogeneity using whole genome and targeted sequencing approaches included samples from four multiple ipsilateral tumors and found all foci examined were clonally related, with additional subclonal driver events and intermingling of subclones across foci [25]. Invasive lobular carcinoma is reported as being more commonly multifocal. Another series showed similar copy number changes but variation in gene expression between multiple foci of invasive lobular carcinoma from the same patient [26]. These results are significant in that taking biopsy samples for molecular studies to determine eligibility for clinical trials is becoming increasingly common, and in the case of multiple tumors a sample from the main lesion may miss genetic heterogeneity across foci even if morphologically similar.

In some studies MSIBC have been found to correlate with known risk factors suggestive of aggressive biology, such as young age, higher grade, HR status, HER-2 status, lymphovascular invasion (LVI) and nodal involvement [17,27]. Other factors may also play a role, such as the loss of E-cadherin, which causes disconnection of cell-cell adhesion and contributes to metastatic potential. A recent study by Weissenbacher et al. demonstrated that MSIBC had significant downregulation in the expression of E-cadherin versus unifocal (UF) lesions [28].

\section{Imaging}

BC typically presents as a spiculated, oval, lobulated hyperdense lesion, with or without microcalcifications, on mammography, and as an ill-defined/spiculated, hypoechoic or inhomogeneously hyperechoic mass with posterior acoustic shadowing on ultrasound. On MRI, BC is seen as an isointense to hypointense mass on T1- and T2weighted images, with early contrast-enhancement, washout and restriction of water signal on diffusion-weighted imaging.

Radiological features of BC may vary greatly; these differences often depend on tumor grade and histological subtype. Hence, sometimes differences in imaging characteristics can predict differences in tumor morphology and biology. ILC frequently invades the normal tissues without invoking the vigorous desmoplastic response that is usually seen in IDC. As a result, the density of ILC is often similar to that of background normal breast fibroglandular tissue, making it mammographically occult $[29,30]$. Changes can be very subtle, such as progressive shrinkage or enlargement or reduced compressibility of the involved breast [29]. Invasive lobular breast cancer is often multicentric (10-15\%), and multiplicity appears more correlated with ILC compared with other histotypes [29]. Due to the limitations of mammography in delineating ILC and the risk of underestimation, other modalities such as sonography and MRI are used to assess the extent of disease [31].

The most common MRI presentation of ILC is that of a mass-like enhancement with irregular or spiculated margins, with rapid uptake and late washout. It may also present as a nonmass-like enhancement with ductal, segmental, regional or diffuse pattern [32].

\section{Preoperative lymphoscintigraphy \& the role of sentinel lymphnode biopsy}

Axillary lymph node staging is also part of the surgical management in MSIBC. BC with multicentric spreading has been considered a relative contraindication to sentinel node biopsy (SNB) due to a presumed higher risk of nodal 
involvement compared with UF BC and concerns that the location of these tumors in different quadrants of the breast might involve more than one dominant lymphatic trunk [33,34]. Therefore, the optimal route of radiocolloid injection has been widely debated, with several different approaches reported in the literature. As a result of these concerns, some researchers have argued that a central injection with a subareolar or periareolar technique may be beneficial. The rationale was based on early studies on the lymphatic system of the breast, in particular on the work of Sappey (1874), a French anatomist.

The author observed that breast lymphatic drainage originated as an intense structure around the lobular glands, and forming subsequently lymphatic trunks alongside the breast ducts centripetally since to the periareolar complex and finally to the axilla [35]. Direct lymph pathways from the injection site to axillary lymph nodes were demonstrated later by Turner-Warwick, who pointed out the possibility that Sappey had overemphasized the role of the subareolar plexus [36]. Direct lymph tracks from the injection site to axillary lymph nodes were displayed later by Turner-Warwick, who underlined the possibility that Sappey had overestimated the involvement of the subareolar plexus [36]. Although there is not yet a clear and definitive understanding of the lymphatic drainage of the breast, different studies demonstrated that it is drained uniformly to a few sentinel lymph nodes, regardless of the injection site of the tracer.

Bauer et al. performed sentinel node mapping in 332 patients with biopsy-proven operable breast cancer or ductal carcinoma in situ through blue dye injection (peritumoral in 83 patients and subareolar in 249 patients) and peritumoral injection of ${ }^{99 \mathrm{~m}} \mathrm{Tc}$-labeled sulfur colloid (all patients) and concluded that the two different localization of tracer delivery identified similar lymph nodes [37]. Klimberg et al. came to the same conclusions by injecting ${ }^{99 \mathrm{~m}} \mathrm{Tc}$-labeled sulfur colloid in the subareolar area of the tumor-bearing breast and isosulfan blue in the peritumoral region of 68 patients with invasive BC and clinically node-negative disease [38]. Kargozaran et al. conducted an analog study on 124 patients and showed a high degree of concordance between subareolar blue dye and peritumoral radiocolloid identification of the sentinel node [39].

Moreover, the validity of subareolar or periareolar injection has been established in a large prospective, multicenter clinical trial on 3961 patients with clinical stage I and II breast cancer. 348 patients had injection with blue dye alone; of the 1762 patients who had injection of ${ }^{99 \mathrm{~m}} \mathrm{Tc}$-sulfur colloid, 1431 had a peritumoral injection while 148 and 183 had a subareolar and periareolar injection, respectively. All patients were submitted to SNB followed by axillary dissection and there were no statistically significant difference in the false-negative rates among the groups, supporting the hypothesis that the lymphatic drainage of the entire breast is to the same few SNs [40].

The use of SNB in multicentric BC is still debated, however, the procedure is routinely performed in patients with clinically negative nodes in many centers, due to the evidence that its accuracy in this disease is comparable with that of published validation studies on UF tumors [41-44]. In one series, positive lymph node involvement was reported in $44-50 \%$ of MSIBC cases compared with $38 \%$ of UF cancers [45]. In a previous study conducted at our Institution, among 337 patients with multicentric BC and clinically negative axilla, having negative SNB and no axillary lymph node dissection (ALND), axillary lymph node recurrence occurred only in three patients after a median follow-up of 5 years [43]. Given the reported data and the simplicity of execution combined with the limited discomfort for the patients, the subareolar injection of radiolabeled colloids has become of the method of choice for multicentric disease in our institution. The injection is performed the same day of surgery, if it is scheduled in the afternoon, or the day before surgery, if it is scheduled in the morning. The injected activity is $15-20 \mathrm{MBq}$ in a volume of 0.1-0.2 ml. Lymphoscintigraphy is then performed as described elsewhere [46]: briefly, planar scintigraphic scans of the involved breast and axillary region, in the anterior and anterior oblique projections, are obtained $20 \mathrm{~min}$, up to $3 \mathrm{~h}$ if needed, after the injection of the radiocolloids. The skin projection of the first node (or nodes) to take up tracer is marked with a suitable pen after the last acquisition.

These premises are inserted in a broader scientific context: the evolution of BC surgical treatment with the ACOSOG Z0011 trial suggested that even patients with limited macrometastasis in the sentinel node (SN) who were treated with breast conserving therapy, whole breast and axillary irradiation in addition to systemic treatment could be spared an ALND, without compromising outcome [47].

\section{Breast surgery}

\section{Breast-conserving surgery}

BCS still seems to be a relative contraindication in case of MSIBC, due to the higher risk of further occult foci in the same breast and the potential for worse cosmetic outcome subsequent to wide and multiple excisions in the same breast [48]. Opportunities for BCS have improved recently due to the introduction of mammoplasty 
techniques, even if evidence from clinical studies on quality of life after mammoplasty in BCS (as defined by Winters et al., 'therapeutic mammoplasty') compared with mastectomy is currently lacking [49]. In the literature, there are no prospective cohort studies or randomized trials comparing BCS with mastectomy, analyzing locoregional recurrence (LRR) as a primary end point in MSIBC: indeed, most of those are retrospective cohort studies [50].

The recent ongoing American College of Surgeons Oncology Group (ACOSOG) Z11102 prospective singlearm trial demonstrated in its initial results that $67.6 \%$ of the women that underwent BCS for MSIBC successfully completed surgery with negative margins, and with an acceptably low rate of conversion to mastectomy (7.1\%). Also, it did not identify any specific patient, imaging or tumor factors that predict patients at increased risk for failure of BCS in the MSIBC population [51]. This study only enrolled patients eligible for BCS and not for mastectomy; however, the SENOMAC study is an ongoing trial that similarly to the Z11102 protocol enroll patients eligible for mastectomy.

BCS in MSIBC finds support in the recent expert consensus in St. Gallen, advocating the feasibility of BCS for surgical treatment in MSIBC, with the crucial assumption of adequate margin clearance and whole-breast radiotherapy (RT) after surgery [52,53]. For this reason, multidisciplinary discussion is vital for appropriate patient selection for BCS in the case of MSIBC. A multidisciplinary team involving Radiologist, Oncologist Surgeon, Medical Oncologist, Radiation Oncologist, Plastic Surgeon, Pathologist plan the surgical procedure with the aim to obtain clear margins with the best cosmetic outcome. The choice of BCS commences with evaluation of the ratio between composite tumor size and breast volume, in conjunction with clinical management based on history and physical examination, accurate imaging studies and histological and biological presurgical information of every cancerous lesion detected in the breast. Of equal importance are the patient's needs and expectations, because BCS represents the preferred method of treatment for many patients [54].

The technical procedure takes into account the necessity for multiple surgical excisions without causing breast deformity and with a low re-excision rate. Tumor size and location along with histopathological and biological features and presence of lymph node involvement will influence the choice of neoadjuvant treatment in MSIBC; the different tumor foci need to be clipped pretreatment to ensure precise localization of the tumor bed to guide surgical excision after primary therapy. Galimberti et al., in line with Senonetwork recommendations, advise specific techniques and preoperative procedures should be carried out to obtain negative margins and reduce the probability of second operations, especially in case of occult cancers. Based on single institutional experience, several procedures including charcoal, metal wire and radioguided occult lesion localization are useful to accurately identify the cancer site [55]. The site and performance of skin incision is also vital for the quality of cosmetic results. Curvilinear skin incisions following Langer's lines (the natural lines of skin tension) are a good choice to achieve the best cosmetic outcomes, with radial incision being a better choice for cancers situated in the lower inner or external quadrants [54]. Excision of a segment of skin is rarely necessary for oncological reasons and not advisable for alteration of the nipple and inframammary crease position.

Oncological safety should be ensured by resection of the tumor with an adequate quantity of surrounding benign glandular tissue, and by reducing intraoperative tumor margin positivity through 'real-time' cancer margin assessments. The specimen should be orientated with specific markers to enable macroscopic assessment of margins status by the pathologist, so resection of further tissue can be performed in case of proximity of tumor to the margins. Frozen section of margins is an option but due to sampling limitations in large oncoplastic specimens does not guarantee negative margins [54,55], it can be a correct and safe practice, in case of MSIBC, to minimize the need for subsequent resections, in particular after oncoplastic procedure. The margin of concern should be clearly indicated, and the specimen should not be sectioned before it is submitted to the pathologist, as this will compromise accurate histological evaluation of the surgical margins [54]. In case of microcalfications, postbiopsy clips or impalpable lesions, 2D specimen x-ray should be performed [55].

Future research will have to take into consideration the genomic profile of each BC lesion in MSIBC: the consequent similarity or heterogeneity in all the cancer foci will guide the correct choice in multidisciplinary treatment. Furthermore, the feasibility of administering RT with boosts to one or more tumor beds after BCS for MSIBC must be determined, as well as the impact of the extent of surgery on 10-year LRR as an outcome measure [50]. The results of trials in progress will enrich our knowledge and provide a sound scientific background for future management guidelines. The final data of ACOSOG Z11102, currently examining LRR following BCS for women with MSIBC [51] and the British MIAMI trial will evaluate the safety of oncoplastic procedures (BCS associated with mammoplasty) in MSIBC [45]. However, the limitation of this study enrolled only 50 patients. The Z11102 study only enrolled patients eligible for BCS and not for mastectomy; however, the SENOMAC study is 
a novel ongoing trial that similarly to the Z11102 protocol enroll patients eligible for mastectomy. The MIAMI trial is also ongoing.

\section{Oncoplastic surgery}

Nowadays, oncoplastic surgery is a well-established approach that combines conserving treatment for BC [56-58] and plastic surgery techniques [59]. It allows wide excisions and prevents breast deformities by the immediate reconstruction of large resection defects [60,61]. Currently, oncoplastic surgery is a steady procedure that joins conserving therapy for BC [56-58] and plastic surgery techniques [59]. It enables wide resections and avoids breast deformities by the immediate reconstruction of consequent defects $[60,61]$.

The cosmetic advantages of this approach have been largely described [62]. Moreover, oncoplastic surgery achieves more accurate tumor resection and free resection margins than standard quadrantectomy or lumpectomy [63,64] and it is definitively useful in extending the indications for breast conservation even in synchronous multicentric BCs [65]. In addition, if a contralateral reduction mammaplasty is performed to achieve similar breast size after large quadrantectomy and reshaping, a 'surgical screening' of the contralateral healthy breast may allow the diagnosis of occult cancers [66].

Among the full range of oncoplastic techniques, there are two fundamentally different approaches: volumereplacement procedures, which combine resection with immediate reconstruction by using local flaps (glandular, fasciocutaneous and latissimus dorsi miniflaps); and volume-displacement procedures, which combine resection with a variety of different breast reduction and reshaping techniques, according to the location of the tumor. Among the all choices of oncoplastic techniques, there are two fundamentally diverse approaches: volume-replacement procedures, which match resection with immediate reconstruction by using local flaps (glandular, fasciocutaneous and latissimus dorsi miniflaps); and volume-displacement procedures, which combine resection with different breast reduction and reshaping techniques, based on the site of the tumor [67]. Both approaches may be performed in case of synchronous multicentric cancers according to tumor size and location and breast size. The ratio of tumor size:breast size is a key point and surely influences the choice between breast conservation and mastectomy. Synchronous multicentric cancers in small breast are treated by mastectomy that represents the gold standard. In fact, local flaps (glandular or fasciocutaneous) are inadequate to reconstruct large quadrantectomy defects resulting in unsatisfactory results and breast asymmetries. Locoregional flaps, such as latissimus dorsi or perforator flaps, from the dorsal region might correct large defects in small breasts but they are not frequently performed since they require more extensive and sophisticated dissection, longer operative time and additional scarring in the donor area.

Synchronous multicentric cancers in large breast are frequently treated by oncoplastic approaches. Several reduction techniques, upper or inferior pedicled or through a round-block periareolar approach, may be indicated bilaterally according to cancer location. In those patients, early complications affected more frequently the breast with cancer than in the healthy breast, as infection, seroma formation and wound dehiscence, due to the more complex surgical approach and the more extensive surgery (including axillary SNB or complete axillary dissection - three levels). However, local complications at the cancer site do not negatively influences delivery of adjuvant treatment as reported by most studies comparing oncoplastic versus conservation alone, showing no difference in surgical complications between the two groups [67].

Although any publication has specifically investigated the outcomes of synchronous multicentric breast cancers treated by oncoplastic surgery, about $25 \%$ of patients with synchronous multifocal cancers are included in the two series published by De Lorenzi et al. [68]. The first study compares a consecutive series of 454 patients who have undergone oncoplastic (ONC) with 908 patients who have undergone conservation alone (control group) over a prolonged period of time at one institution. The authors conclude that ONC is a safe and reliable treatment option for the managing of invasive BC. In the second paper [68], a series of 193 T2-patients who have undergone oncoplastic surgery were compared with $386 \mathrm{~T} 2$-patients who have undergone mastectomy over a prolonged period of time. Overall survival (OS) and disease-free survival are similar within the two groups. The authors conclude that the study provides the best available evidence to suggest that ONC approach is a safe and reliable treatment for managing invasive $\mathrm{p} T 2$ breast cancers.

\section{Mastectomy}

In the so-called nipple-sparing mastectomy (NSM) process, the breast tissue anatomically localized by splitting of the superficial fascia delimited by the large infraclavicular muscle bundle, the midline of the sternum, the front edge of latissimus dorsi and the lower edge of major pectoralis on the sixth rib should be removed en bloc. The patient 
must be informed of residual cancer risk from remaining glandular cells even in the most accurate mastectomies. Respecting the limits of the dissection and saving the inframammary folds allow a better breast reconstruction.

Several skin incisions have been proposed in the literature in order to remove en bloc the glandular breast tissue on the one hand, and maintaining the entire breast envelope on the other. The upper outer linear incision is most commonly used because it safeguards vascularization of the nipple areola complex and easily removes all the glandular tissue. However, it is not the right cosmetic approach for every patient, and consideration must be given that during healing, the scar could retract the nipple areola complex toward the axillary tail. Moreover, there are also nonconventional surgical approaches tailored to the individual patient [69], when the classic incision is not possible [70].

Technical innovations have already made feasible robotic NSM, and this has been reported as well tolerated, safe and associated with good cosmetic outcomes. The robotic technique reproduces the open approach, and assisted by the accuracy, flexibility and control given by the robot allows the surgeon to perform complete mastectomy through a tiny hidden extramammary incision [71,72]. A randomized clinical trial comparing open NSM and robotic NSM in prophylactic surgery is on going (clinicaltrials.gov number NCT03440398). However, patients with moderate and/or severe breast ptosis are usually not eligible for this classic surgical approach for NSM. Different patterns for skin incisions are classified as hemi-periareolar, round block, vertical pattern and wise pattern approaches [73]. The selection criteria for NSMs include: no areolar or nipple retraction; no nipple discharge-containing blood; no inflammatory disease and negative intraoperative retroareolar margins on frozen sections. Multicentric disease is not a contraindication.

SNB is indicated in case of mastectomy in patients with clinically negative nodes, and ALND still represents the standard treatment in cases of macrometastases that affect any SN. Instead, in the case of SN with micrometastasis and/or isolated tumor cells, ALND is not indicated. The IBCSG 23-01 multicenter, randomized, noninferiority, Phase III trial, enrolled 465 patients randomly assigned to ALND and 469 to no ALND. Patients had one or more SNs with micrometastases. The IBCSG 23-01 trial published recently the results from 10 years of observation. This study has confirmed that ALND is not indicated in patients with micrometastatic SNs [74].

The SENOMAC trial is a new ongoing multicenter noninferiority study. The hypothesis of this trial is 'no axillary clearance in BC patients with one to two SNs with macrometastasis will not worsen BC-specific survival.' About 3500 patients will enrolled for this study (IN PRESS), and the trial will closed in December 2022.

\section{Mastectomy with breast reconstruction}

Options for postmastectomy reconstruction include implant-based reconstructions and autologous tissues [75]. The reconstruction is usually performed at the same time of mastectomy and called 'immediate.' Rarely, it is postponed in a second surgery (delayed reconstruction). The type of mastectomy (skin sparing or nipple-areola sparing), breast size and surgical skin incisions impact on the type of reconstruction, as well as patient demand and co-morbidities. Plastic surgeons need to deal with different issues, tailoring patient therapeutic strategies. Unfortunately, not all women are suitable for nipple-areola sparing mastectomy. To reduce possible complications, as mastectomy flap necrosis, and to improve cosmetic outcome, skin sparing mastectomy is more indicated for patients with large (D cup or larger) ptotic breast or in cases of multiple previous scars [76-78].

\section{Implant-based reconstruction}

The improved manufacture of implants associated to the development of new surgical techniques raised the popularity of implant-based breast reconstruction. The main advantages are short operative time, no donor site morbidity and less recover time. However, implant is not a lifelong medical device [79]. The main advantages are brief operative time, no donor site morbidity and minor recover time. However, implant is not a permanent medical device [79] and patients must be informed about revisional surgery and implant-related complications.

\section{One-stage implant reconstruction}

This is probably one of the simplest and effective procedure of immediate reconstruction supposing that the surgeon selects a good candidate and implant model [80]. This is probably one of the simplest and valid procedure of immediate reconstruction presuming that the surgeon chooses a good candidate and implant model [80]. Anatomical silicone gel implants are usually used to mimic the natural shape of the breast. 


\section{Two-stage (expander-implant) implant reconstruction}

In the first stage, a tissue expander is placed in the muscular pocket, behind the pectoralis major muscle and the serratus anterior muscle or its fascia. The tissue expander is partially filled with saline solution. The injection port is usually integrated on the expander surface, the old models had a distant port. The expansion usually starts 2-3 weeks postoperatively, then every few weeks until the final volume is reached, which is usually slightly bigger than the definite prosthesis. Expander-implant change is planned few months after primary surgery depending on postoperative adjuvant treatments. For instance, such as prolonged medical or chemotherapy or pregnancyassociated breast cancer, it can be substituted over the year [81].

The expansion usually starts 2-3 weeks postoperatively, then every few weeks until the final volume is obtained, which is usually slightly bigger than the definite prosthesis. Expander-implant change is projected few months after primary surgery related to postoperative adjuvant treatments. For instance, in the case of adjuvant chemotherapy or prolonged medical treatments, or in the presence of breast cancer associated with pregnancy, it can be replaced over the year [81].

\section{Autologous tissue reconstruction}

Many patients prefer autologous reconstruction, if possible, because of the similarity to natural breast, stability overtime of the long-term result and the anxiety about using foreign material/implants. Autologous reconstruction encompasses a broad range of procedures incorporating the patient's own tissues to recreate the breast mound (pedicled and free flaps, fat grafting). On the contrary, these techniques require significantly long surgical time and they are associated to increased donor-site morbidity [82].

There are various types of autologous reconstructions:

- Pedicled transverse rectus abdominis musculocutaneous flap;

- Free transverse rectus abdominis musculocutaneous flap;

- Deep inferior epigastric perforator flap;

- Latissimus dorsi flap.

In case of unilateral mastectomy for MSIBC, autologous reconstructions allow better cosmetic results. In fact, unilateral implant reconstruction generally fails to fully 'match' the contralateral breast without a bra and over time this asymmetry actually worsen as the contralateral natural breast becomes more ptotic and changes in size with patient weight gain or loss. On the contrary, bilateral reconstructions with implants may be really satisfactory, especially in case of small to medium breasts when nipple and areola are preserved. The differences in the long term with both options (implants or autologous tissues) are not significant [83].

The complication rates after reconstruction vary considerably, 8-64\% in the literature [84]. This may depend on patient selection or the definition of complications. There is no consensus on what should be considered a complication. The most common complication is early wound necrosis/epidermolysis usually involving the nippleareola complex or skin edges, sometimes leading to implant loss [85]. In addition, late complications concern cosmetic issues, almost always leading to additional surgery. In this respect, patients should be informed preoperatively that an optimal cosmetic reconstruction cannot unconditionally be achieved in just one single operation.

The late complications regard cosmetic questions and often require additional surgery. In this contest, the patient should always be informed preoperatively of the uncertainty of obtaining an optimal cosmetic result in a one single operation. Late complications include also those related to silicone breast implants, as recent scientific reports suggest their possible role in chronic stimulation, autoimmune response and subsequent risk of developing a breast implant associated-anaplastic large cell lymphoma.

\section{Adjuvant treatments}

Approach at BC treatment is based on clinical stage, histopathology and biomarker pattern [14,86]. Also, menopausal status, age at onset and health status influenced treatment's choice. These factors are related significantly with survival and explain most of the variations observed in clinical outcomes among patients with BC. Overviews by the Early BC Trialists' Collaborative Group have well recognized the benefit of adjuvant polychemotherapy in early BC patients irrespective of age, the use of tamoxifen, HR status, nodal status and other tumor characteristics, reducing the annual odds of disease recurrence and BC mortality [87]. In addition, these overviews have also shown a reduction in the risk of $\mathrm{BC}$ mortality by approximately a third with the use of adjuvant endocrine therapy in patients with 
ER-positive BC regardless of PR status, age, nodal status and the use of chemotherapy. Given the growing knowledge treatments were assessed in light of their intensity, duration and side effects, seeking where appropriate to escalate or de-escalate therapies based on likely benefits as predicted by tumor stage and tumor biology.

Due to the growing knowledge, treatments have been evaluated in relation to their intensity, duration and side effects, trying, if necessary, to intensify or reduce the therapies based on probable benefits, as foreseen by the tumor stage and biology. In the setting of MSIBC, the choice of the best adjuvant treatment may appear simple. However, currently, there are no consistent evidence-based guidelines for the management of MSIBC, and treatment decisions are often made based on the primary tumor with the most high-risk features. However, currently there are no substantial evidence-based guidelines for the management of MSIBC and therapeutic decisions are often based on the most high-risk characteristics of the primary tumor. This could be particularly true for different tumors with different biology, but in case of multicentric ER-positive, HER2-negative, node-negative BC, this distinction may be difficult as the tumors may appear quite similar by standard histopathologic criteria. Gene expression signatures such as the 21-gene RS have been demonstrated to predict chemotherapy benefit in this group of patients, and as discussed in adjuvant treatments this may be different in up to $22 \%$ of MSIBC, particularly if the tumor foci are of different grade or histological type [22].

It is well known that heterogeneity is a hallmark of malignancy; it can be appreciated within a single tumor or between primary breast carcinomas and synchronous lymph node metastases. This aspect should be particularly underlined in case of MSIBC with different biology and positive nodes at diagnosis. The status of the axillary lymph nodes is the most important single prognostic factor for patients with BC and the correct biological characterization of the node metastases can help the clinicians to choose the most appropriate treatment. In particular, this aspect could be crucial in the decision-making process as to whether or not to give neoadjuvant chemotherapy. The association of adjuvant systemic therapy with improved survival is clearly demonstrated.

However, Mauri et al. did not find any difference in OS, disease progression and distant disease recurrence between neoadjuvant and adjuvant treatment in a meta-analysis of nine trials with around 4000 patients [88]. In relation to the scientific evaluation of therapeutic benefits of neoadjuvant treatment, research could find future potential opportunities in two promising prospects:

- In vivo assessment of therapeutic efficacy, obtaining important prognostic and predictive information based on the response to treatment, the analysis of the extent and characteristics of the residual disease and the identification of biomarkers of drug sensitivity and resistance;

- Accelerated approval of new drugs [89,90].

Randomized trials of chemotherapy demonstrate similar long-term outcome when patients receive the same regimen preoperatively compared with postoperatively. A recent meta-analysis demonstrated that complete pathological response decreased with the increasing of clinical tumor size (trend $p<0.0001$ ) in particular in cases of ERnegative tumors than in those ER-positive $(\mathrm{p}<0.0001)$ and in poorly differentiated tumors than in well or moderately differentiated (trend $\mathrm{p}=0.001$ ). Furthermore, complete pathological response was higher in the one trial that associated anthracycline and taxane drugs than in the other trials $(\mathrm{p}<0.0001)$. Age, nodal status and planned local therapy did not related with response [91]. Patients with MSIBC are not always eligible to participate in neoadjuvant clinical trials, however, the histological confirmation of at least two lesions could be considered and this attitude should be also used in clinical practice. In case of patients with multicentric tumors with different biology and with positive axillary nodes, the assessment of biology on the lymph nodes should also be considered.

\section{Radiotherapy}

The efficacy of whole breast irradiation in MSIBC disease

Whole breast irradiation (WBI) after BCS has been proven to be effective against residual microscopic foci of BC, as evidenced by the fact that omission leads to an increased local recurrence (LR) rate of up to $39.2 \%$ in historical landmark trials [91,92]. LRs occur mainly at or near the original tumor bed but distant quadrants can also be affected with incidence as high as $42 \%$, especially in young patients [93]. Whatever the clinical and biological significance of occult foci of cancer, the overall effect of WBI is satisfactory in terms of local control, achieving rates as high as $94 \%$ at 10 years for stage I-II disease [94,95]. Nowadays, thanks to advance in diagnostic imaging, often including magnetic resonance, MSIBC have become more clinically apparent. BCS might remain a feasible option as long as it abides by the principles of oncological clearance. 
In MSIBC, BCS raises a series of issues for radiation oncologists. First, oncoplastic techniques involving tissue translocation are frequently applied in this setting [96], making the location of the original tumor difficult. Therefore, a higher dose to the tumor bed might be not properly delivered and its omission could increase the risk of local relapse, especially in young women and grade 3 tumors, where the use of boost significantly impacts on local control [97]. Second, concerns regarding the increased risk of moderate to severe fibrosis to a large breast volume receiving the boost dose [98] in the attempt to cover the entire area of MSIBC, potentially resulting in worse cosmetic outcomes. In addition, MSIBC called into question the overall efficacy of WBI after BCS. Some authors reported negative results when BCS is performed for macroscopically MSIBC $[99,100]$, based on the fact that the neoplastic residual burden was considered so great that WBI could not control it. Chung et al. recently investigated a cohort of MSIBC patients undergoing BCS and found that both relapse-free survival and OS were significantly reduced in the group of MSIBC compared with UF BC [101].

Similarly, in a pair case-control cohort [102], the long-term actuarial local control rates for MSIBC and UF tumors were 88 and 97\%, respectively $(\mathrm{p}<0.001)$. On multivariate analysis, MSIBC was confirmed to be associated with higher LR rate after controlling for other variables, including surgery type. However, other reports, including systemic therapy and greater attention to surgical margin status [103], did not show any increased rate of LR after BCS compared with mastectomy [104]. In addition, closer adherence to guidelines emerged as a key aspect to reverse the difference in local control and survival among UF and MSIBC groups in a multicenter study analyzing 8935 patients [105].

The reported inferior local control of MSIBC, regardless of type of treatment, can be partially attributable to tumor extension and partly to the more aggressive nature of MSIBC, as exhibited by the properties of clones of neoplastic cells enabling spread across the breast.

\section{Partial breast irradiation \& the risk of multicentricity}

$\mathrm{BC}$ RT has become more and more risk adapted over recent years with a trend toward a reduction in intensity and extent. The rationale of delivering RT to the tumor bed, so-called partial breast irradiation (PBI), is based on evidence that most ipsilateral tumor recurrences occur in the same site as the primary BC $[94,106]$. While macroscopically evident MSIBC represent an apparent contraindication to PBI, the same applies to all clinical situations where the probability of occult MSIBC is not negligible. In fact, since the effect of PBI is limited to the index quadrant, it is of paramount importance to select patients at low risk of harboring occult microscopic disease in the remaining breast, so that local control is not inferior to that of WBI.

Several guidelines (American Brachytherapy Society [ABS] [107], American Society for Radiation Oncology [ASTRO] [108], European Society for Radiotherapy and Oncology [ESTRO] [109]) have been published to define eligible patients. The selection criteria for the ideal candidate are based on clinical, histopathological and biomolecular features that are well known to be associated with a low risk of LR. The ESTRO and ASTRO guidelines for $\mathrm{PBI}$ include age $\geq 50$ years, unicentric, UF pT1 (pT2 $\leq 30 \mathrm{~mm}$ for ESTRO) pN0, no lobular histology (which is instead accepted by the ABS), without the presence of an extensive intraductal component and LVI, with negative margins of at least $2 \mathrm{~mm}$. Regarding hormonal receptors, ASTRO only requires positive expression. The literature has clearly shown that the greater the number of risk factors, the higher the risk of LR across the breast $[110,111]$. Tendulkar $e t$ al. pointed out the significant association of some tumor features with additional ipsilateral disease, such as lobular histology, pathologic T2 and AJCC stage II [112]. In particular, the exclusion of ILC in the ASTRO and ESTRO guidelines [109] was agreed on the base of MSIBC nature of such histology and on evidence from retrospective studies [113] and the Christie Hospital randomized trial [114], which showed an increased rate of LR (42 vs 17\%). Conversely, ABS guidelines included all invasive subtypes, alongside ILC, embracing the concept that failure is more due to poor tumor biology rather than the type of treatment [107]. In more recent randomized trials comparing PBI and WBI, ILC has been handled in different ways [115]: some trials excluded it from eligibility criteria, such as the TARGIT, the National Institute of Oncology Hungarian, the RAPID and the IMPORT LOW trials, while others did not. Among the published trials including ILC, the GEC-ESTRO and the University of Florence Phase III trials and the Phase II German-Austrian trial did not show any difference related to histology [116]. In a single institution series of patients treated with intraoperative RT with electrons comparing 252 ILC with 1921 IDC, the rate of LR was 1.96-times higher for ILC. However, difference in local control became nonsignificant when larger intraoperative RT collimator were used, underlining the importance of an extended RT field to reach microscopic neoplastic foci surrounding ILC [117]. With a view to improving selection, MRI is often used because of its greater ability to identify additional neoplastic foci compared with conventional radiology. Although not 


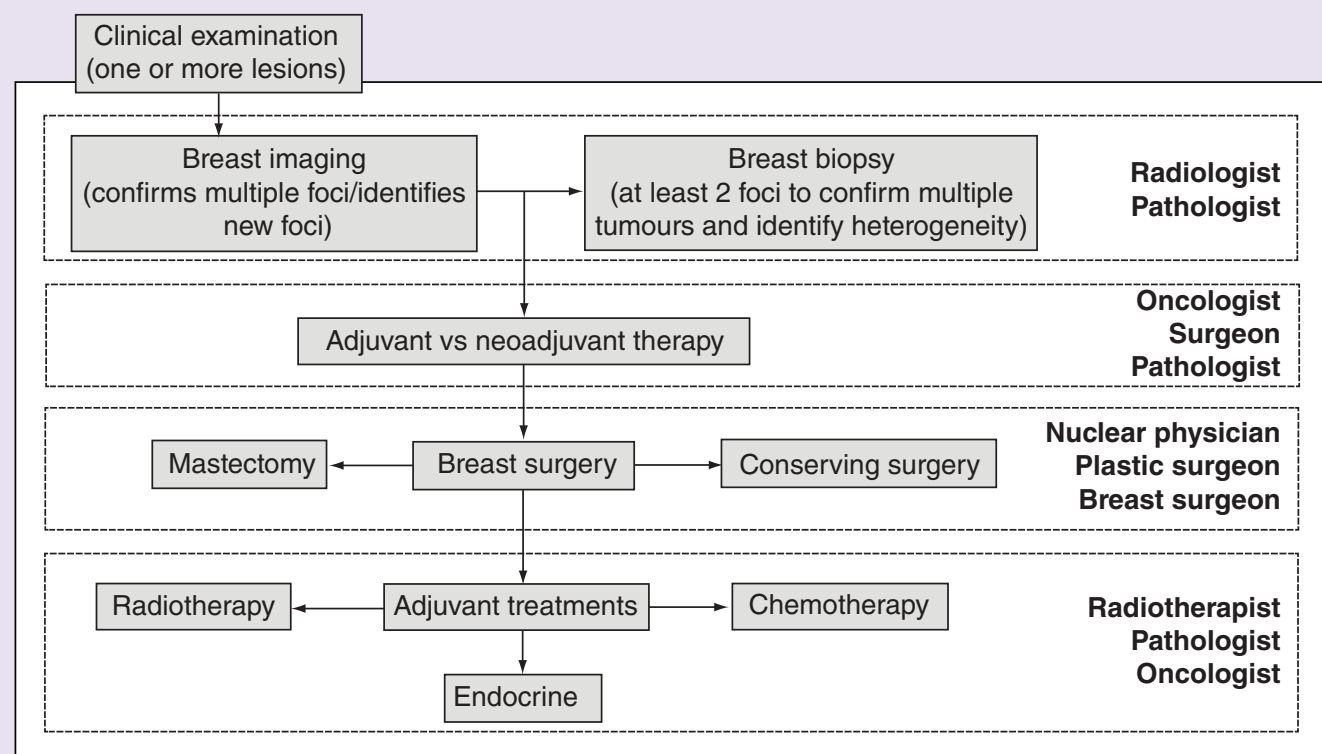

Figure 1. Flowchart for a multidisciplinary management of multiple synchronous (multifocal or multicentric) ipsilateral breast cancer patients.

routinely recommended in clinical practice, the use of magnetic resonance is supported by the European Society of BC Specialists (EUSOMA) Working Group for PBI decision-making [118].

\section{Histology \& multicentricity}

ILC is typically associated with more occult disease than IDC [119], as several pathological studies have documented. Radiologically, MSIBC foci can be found up to $25 \%$ of the patients with ILC, compared with about $10 \%$ for IDC [120]. For this reason, the safe delivery of BCS has been a matter of debate, as BCS is seen as merely debulking and the efficacy of WBI in multiple synchronous (multifocal or multicentric) ipsilateral BC is questioned by the expected greater tumor burden, especially when negative margins are not obtained at initial BCS. The reported positive margin status ranged from 18 to 63\% [121], especially in presence of extensive intraductal component, larger tumor size and high grade [122] and represents an important risk factor for LR after BCS in patients without re-excision or with positive compared with negative re-excisions [123]. Currently, there is no evidence of increased incidence of LRs when BCS is performed and clear margins are achieved [119]. In a large French series of over 11,000 patients with long follow-up treated at the Institute Curie, ILC patients receiving BCS had similar LR and OS rates to those affected by IDC [124], prompting discussion around the high radiosensitivity of ILC [121].

\section{Is multicentricity an indication for postmastectomy RT?}

MSIBC is not an independent risk factor of LR such as to warrant postmastectomy RT (PMRT). Therefore, MSIBC by itself does not influence the recommendation for adjuvant RT in the mastectomy setting. The adverse patient outcome of MSIBC can be explained by the more frequent association with axillary node involvement compared with UF tumors with similar stage of disease [125]. In the study by Coombs and Boyages $52.1 \%$ of MSIBC had axillary node involvement compared with $37.5 \%$ with UF BC ( $p=0.007)$ [7]. Not only is axillary involvement more frequent, but the nodal burden is also heavier. In the study conducted by Weissenbacher et al. [28], 30.9\% of $\mathrm{BC}$ patients in the MSIBC group were classified as $\mathrm{pN} 2$ and $\mathrm{pN} 3$. Some authors attributed the nodal positivity to the total tumor load resulting in a more advanced stage [126], while others suggested that MSIBC is a heterogeneous disease and that lymph node spread reflects the size of the more aggressive primary lesion [27]. The increased use of PMRT and chemotherapy for MSIBC in the population of 1322 patients with T1-3 invasive BC, analyzed by Cabioglu et al. [27], was motivated by their more advanced stage at presentation compared with UF BC. When patients were grouped according to stage, the difference in terms of rates of systemic metastases, LR, disease-free survival or OS between MSIBC and UF disappeared. This observation has been confirmed by other reports. In 
a group of 906 patients classified as having MSIBC and UF disease, Lynch et al. described no difference in local control between the MSIBC and UF groups treated with BCS, mastectomy alone or PMRT [127]. There is conflict in the literature as to differences between MSIBC and UF disease with regard to age, nuclear grade, histologic grade, LVI, and ER and PgR status, which can be key factors in the decision making for PMRT [17,27]. The role of PMRT in patients with one to three positive nodes after axillary dissection is controversial [128], and MSIBC should not be considered as an additional risk factor to justify PMRT. In a small subgroup of patients analyzed in the study by Katz et al., MSIBC in T1-2 N1a tumors was not an independent risk factor for LR [129].

\section{Conclusion}

MSIBC with heterogeneous histopathology represents a controversial clinical condition, widely debated and studied in the literature, without an international consensus on the definition and its clinical management. The actual incidence of MSIBC is unknown, however, the frequency is increasing due to improvements in sensitivity of imaging and use of breast MRI for $\mathrm{BC}$ screening and staging. This heterogeneous disease requires particular attention in the management, since MSIBC tends toward more aggressive biology and higher rates of nodal positivity [130].

Once MSIBC is diagnosed, surgeons need to carefully weigh up BCS versus mastectomy options to optimize oncological safety. Mastectomy rates have increased in the last decade due in part to the diagnosis of MSIBC, however, BCS with achievement of clear margins is feasible in selected cases. Based on the contemporary BC care approach, the management of this heterogeneous disease warrants shared decision-making inside a multidisciplinary team (Figure 1). In this multidisciplinary review, we considered the different faces of this rare disease offering practical guidance for clinicians after a diagnosis of MSIBC.

We are strongly convinced that MSIBC presents a different genetic pathway in comparison to UF BC. Further studies, as the Next-Generation Sequency, could compare somatic genetic results between UF and multicentric BC, to identify some possible tumor differences.

\section{Future perspective}

The current trend of scientific research in MSIBC's management is showing that, thanks to the increasingly early breast cancer clinical detection and targeted therapies development, LR rate and cosmetic outcome after BCS for MSIBC appear similar to those of UF neoplasia, at the same stage. Near future looks at results from prospective and clinical randomized trials, already ongoing, analyzing the BCS validity respect to mastectomy and the significant role of systemic treatments based on the biology of every multiple lesions, in terms of LR and OS rate. A novel rigorous look to genetic pattern's heterogenicity of each different focus will represent an even more targeted and specific therapeutic approach for MSIBC.

\section{Executive summary}

- Multicentric breast cancer with heterogeneous histopathology: a multidisciplinary review.

- The new acquisitions in imaging, thanks to the introduction of the ultrasound and, more recently, of MRI in the diagnostic route of breast cancer, associated with increased screening, have allowed obtaining greater sensitivity in multiple synchronous (multifocal or multicentric) ipsilateral breast cancers (MSIBC) diagnosis.

- There are not so many studies about heterogeneity of each focus in MSIBC, in particular in terms of different histopathology: various results and motley conclusions emerge from few studies addressed to analyze histological and immunohistochemical features of tumor foci in MSIBC.

- There is no a standard method in surgical management of MSIBC.

- The choice to perform breast conservation surgery (BCS) for MSIBC in the last years has improved, thanks also to the support of oncoplastic technique, even if there are not clinical evidence studies on quality of life after mammoplasty in BCS compared with mastectomy.

- In the literature, there are not significative prospective cohort studies nor randomized trials comparing BCS with mastectomy, analyzing as primary end point locoregional recurrence in MSIBC: indeed, most of those are retrospective cohort studies.

- In a clinically negative axilla, sentinel lymphnode biopsy is a feasible, safe and accurate surgical procedure in axillary staging in MSIBC. No difference in lymph node recurrence or overall survival has been found among patients undergoing sentinel lymphnode biopsy for MSIBC versus unifocal disease.

- Technological improvements in radiotherapy and the increasingly clinical value of target neoadjuvant/adjuvant therapies could support a more conservative surgical management.

- Multidisciplinary approach is crucial in patient's selection for surgical and adjuvant treatments in the case of MSIBC, in the future also supported by novel genetic researches. 
Financial \& competing interests disclosure

This work was partially supported by the Italian Ministry of Health with Ricerca Corrente and $5 \times 1000$ funds, by the Fondazione IEO-CCM and by the Umberto Veronesi Foundation. The authors have no other relevant affiliations or financial involvement with any organization or entity with a financial interest in or financial conflict with the subject matter or materials discussed in the manuscript.

No writing assistance was utilized in the production of this manuscript.

\section{References}

Papers of special note have been highlighted as: • of interest; $\bullet \bullet$ of considerable interest

1. Hortobagyi GN, Connolly JL, D’Orsi CJ et al. Emerging prognostic factors for clinical care risk assessment models (2016). www.cancerstaging.org

2. Kheirelseid EAH, Jumustafa $\mathrm{H}$, Miller $\mathrm{N}$ et al. Bilateral breast cancer: analysis of incidence, outcome, survival and disease characteristics. Breast Cancer Res. Treat. 126(1), 131-140 (2011).

3. Vrabec Branica B, Smojver Jezek S, Juros Z, Neralić Meniga I Križanac Š. Synchronous bilateral breast carcinoma with two different morphology subtypes: a case report. Coll. Antropol. 34(2), 701-704 (2010).

4. Salgado R, Aftimos P, Sotiriou C, Desmedt C. Evolving paradigms in multifocal breast cancer. Semin. Cancer Biol. 31, 111-118 (2015).

5. Hortobagyi GN, Connolly JL, D’Orsi CJ et al. AJCC Cancer Staging Manual (8th Edition). NY, USA (2017).

6. Pekar G, Gere M, Tarjan M et al. Molecular phenotype of the foci in multifocal invasive breast carcinomas: intertumoral heterogeneity is related to shorter survival and may influence the choice of therapy. Cancer 120(1), 26-34 (2014).

- Interesting analysis underlying the significance in determine molecular phenotyping of multiple foci of ipsilateral breast cancer in relation to specific therapeutic planning and subsequent outcome. Similarity or heterogeneity in all the cancer foci will guide the correct choice in multidisciplinary treatment, furthermore in the contest of studying the feasibility of administer one or more tumor bed radiotherapy boost after breast conservation surgery in multiple synchronous (multifocal or multicentric) ipsilateral breast cancers (MSIBC). It remarks at the same time how, currently, intertumoral heterogeneity represents a challenge in clinical practice. This issue is not so widely studied in the literature and this study is a significative contribution on this issue.

7. Coombs NJ, Boyages J. Multifocal and multicentric breast cancer: does each focus matter? J. Clin. Oncol. 23(30), 7497-7502 (2005).

8. Vlastos G, Rubio IT, Mirza NQ et al. Impact of multicentricity on clinical outcome in patients with T1-2, N0-1, M0 breast cancer. Ann. Surg. Oncol. 7(8), 581-587 (2000).

9. Lagios MD. Multicentricity of breast carcinoma demonstrated by routine correlated serial multicentric breast carcinoma subgross and radiographic examination. Cancer 40(4), 1726-1734 (1977).

10. Page DL. Special types of invasive breast cancer, with clinical implications. Am. J. Surg. Pathol. 27(6), 832-835 (2003).

11. Yerushalmi R, Hayes MM, Gelmon KA. Breast carcinoma - rare types: review of the literature. Ann. Oncol. 20(11), 1763-1770 (2009).

12. Weigelt B, Geyer FC, Reis-Filho JS. Histological types of breast cancer: how special are they? Mol. Oncol. 4(3), 192-208 (2010).

13. Nagao T, Kinoshita T, Hojo $\mathrm{T}$ et al. The differences in the histological types of breast cancer and the response to neoadjuvant chemotherapy: the relationship between the outcome and the clinicopathological characteristics. Breast 21(3), 289-295 (2012).

14. Lakhani SR, Ellis IO, Schnitt SJ, Tan PH, van de Vijver MJI. WHO Classification of Tumours of the Breast (4th Edition). WHO OMS, Nottingham, UK.

15. Choi Y, Kim EJ, Seol H et al. The hormone receptor, human epidermal growth factor receptor 2, and molecular subtype status of individual tumor foci in multifocal/multicentric invasive ductal carcinoma of breast. Hum. Pathol. 43(1), 48-55 (2012).

16. Chou S, Khan T, Mahajan H, Pathmanathan N. Predicting discordant HER2 results in ipsilateral synchronous invasive breast carcinomas: experience from a single institution. Pathology 47(4), 637-640 (2015).

17. Kanumuri P, Hayse B, Killelea BK et al. Characteristics of multifocal and multicentric breast cancers. Ann. Surg. Oncol. 22(8), 2475-2482 (2015).

18. Boros M, Ilyes A, Nechifor Boila A et al. Morphologic and molecular subtype status of individual tumor foci in multiple breast carcinoma. A study of 155 cases with analysis of 463 tumor foci. Hum. Pathol. 45(2), 409-416 (2014).

19. East EG, Pang JC, Kidwell KM, Jorns JM. Utility of estrogen receptor, progesterone receptor, and HER-2/neu analysis of multiple foci in multifocal ipsilateral invasive breast carcinoma. Am. J. Clin. Pathol. 144(6), 952-959 (2015).

20. Pekmezci M, Szpaderska A, Osipo C, Erşahin Ç. Evaluation of biomarkers in multifocal/multicentric invasive breast carcinomas. Int. J. Surg. Pathol. 21(2), 126-132 (2013).

21. Buggi F, Folli S, Curcio A et al. Multicentric/multifocal breast cancer with a single histotype: is the biological characterization of all individual foci justified? Ann. Oncol. 23(8), 2042-2046 (2012).

22. Toole MJ, Kidwell KM, Van Poznak C. Oncotype dx results in multiple primary breast cancers. Breast Cancer 8, BCBCR-S13727 (2014). 
- A novel notable perspective related to genetic role in clinical management of MSIBC: in particular, it is suggested the importance of Oncotype Dx testing in each primary tumor in affecting chemotherapy recommendations and treatments decision, through the retrospective analysis of a cohort of hormone receptor-positive, lymph node-negative breast cancer patients.

23. Biermann J, Parris TZ, Nemes S et al. Clonal relatedness in tumour pairs of breast cancer patients. Breast Cancer Res. 20(1), 96 (2018).

24. Desmedt C, Fumagalli D, Pietri E et al. Uncovering the genomic heterogeneity of multifocal breast cancer. J. Pathol. 236(4), 457-466 (2015).

25. Yates LR, Gerstung M, Knappskog S et al. Subclonal diversification of primary breast cancer revealed by multiregion sequencing. Nat. Med. 21(7), 751-759 (2015).

26. Norton N, Advani PP, Serie DJ et al. Assessment of tumor heterogeneity, as evidenced by gene expression profiles, pathway activation, and gene copy number, in patients with multifocal invasive lobular breast tumors. PLoS ONE 11(4), e0153411 (2016).

27. Cabioglu N, Ozmen V, Kaya $\mathrm{H}$ et al. Increased lymph node positivity in multifocal and multicentric breast cancer. J. Am. Coll. Surg. 208(1), 67-74 (2009).

28. Weissenbacher T, Hirte E, Kuhn C et al. Multicentric and multifocal versus unifocal breast cancer: differences in the expression of E-cadherin suggest differences in tumor biology. BMC Cancer 13(1), 361 (2013).

29. Lopez JK, Bassett LW. Invasive lobular carcinoma of the breast: spectrum of mammographic, US, and MR imaging findings. Radiographics 29(1), 165-176 (2009).

30. Brem RF, Ioffe M, Rapelyea JA et al. Invasive lobular carcinoma: detection with mammography, sonography, MRI, and breast-specific gamma imaging. Am. J. Roentgenol. 192(2), 379-383 (2009).

31. Johnson K, Sarma D, Hwang ES. Lobular breast cancer series: imaging. Breast Cancer Res. 17(1), 94 (2015).

32. Yeh ED, Slanetz PJ, Edmister WB et al. Invasive lobular carcinoma: spectrum of enhancement and morphology on magnetic resonance imaging. Breast J. 9(1), 13-18 (2003).

33. Veronesi U, Paganelli G, Galimberti V et al. Sentinel-node biopsy to avoid axillary dissection in breast cancer with clinically negative lymph-nodes. Lancet 349(9069), 1864-1867 (1997).

34. Giard S, Chauvet MP, Penel N et al. Feasibility of sentinel lymph node biopsy in multiple unilateral synchronous breast cancer: results of a French prospective multi-institutional study (IGASSU 0502). Ann. Oncol. 21(8), 1630-1635 (2010).

35. Suami H, Pan WR, Taylor GI. Historical review of breast lymphatic studies. Clin. Anat. 22(5), 531-536 (2009).

36. Turner-Warwick RT. The lymphatics of the breast. Br. J. Surg. 46(200), 574-582 (1959).

37. Bauer TW, Spitz FR, Callans LS et al. Subareolar and peritumoral injection identify similar sentinel nodes for breast cancer. Ann. Surg. Oncol. 9(2), 169-176 (2002).

38. Klimberg VS, Rubio IT, Henry R et al. Subareolar versus peritumoral injection for location of the sentinel lymph node. Ann. Surg. 229(6), 860-864, (1999).

39. Kargozaran H, Shah M, Li Y et al. Concordance of peritumoral technetium 99m colloid and subareolar blue dye injection in breast cancer sentinel lymph node biopsy. J. Surg. Res. 143(1), 126-129 (2007).

40. Chagpar A, Martin RC, Chao C et al. Validation of subareolar and periareolar injection techniques for breast sentinel lymph node biopsy. Arch. Surg. 139(6), 614-628 (2004).

41. Kumar R, Jana S, Heiba SI et al. Retrospective analysis of sentinel node localization in multifocal, multicentric, palpable, or nonpalpable breast cancer. J. Nucl. Med. 44(1), 7-10 (2003).

42. Tousimis E, Van Zee KJ, Fey JV et al. The accuracy of sentinel lymph node biopsy in multicentric and multifocal invasive breast cancers. J. Am. Coll. Surg. 197(4), 529-535 (2003).

43. Gentilini O, Veronesi $\mathrm{P}$, Botteri $\mathrm{E}$ et al. Sentinel lymph node biopsy in multicentric breast cancer: five-year results in a large series from a single institution. Ann. Surg. Oncol. 18(10), 2879-2884 (2011).

44. Holwitt DM, Gillanders WE, Aft RL et al. Sentinel lymph node biopsy in patients with multicentric/multifocal breast cancer: low false-negative rate and lack of axillary recurrence. Am. J. Surg. 196, 562-565 (2008).

45. Winters ZE, Benson JR. MIAMI Trial Management Group. Surgical treatment of multiple ipsilateral breast cancers. Br. J. Surg. 105(5), 466-468 (2018).

-• Supports future research with randomized trials to study the impact of the extent of surgery for MIBC, with specific reference to MIAMI (multiple ipsilateral breast-conserving surgery versus mastectomy) trial, analyzing as primary aim the 10-years locoregional recurrence.

46. De Cicco C, Trifirò G, Intra M et al. Optimised nuclear medicine method for tumour marking and sentinel node detection in occult primary breast lesions. Eur. J. Nucl. Med. Mol. Imaging 31(3), 349-354 (2004).

47. Giuliano AE, McCall L, Beitsch P et al. Locoregional recurrence after sentinel lymph node dissection with or without axillary dissection in patients with sentinel lymph node metastases: the American College of Surgeons Oncology Group Z0011 randomized trial. Ann. Surg. 128, 12-21 (2010).

48. Nijenhuis MV, Rutgers EJT. Conservative surgery for multifocal/multicentric breast cancer. Breast 24(Suppl. 2), S96-S99 (2015). 
49. Winters ZE, Horsnell J, Schmid P et al. Time for a randomised clinical trial evaluating breast conserving surgery compared to mastectomy in ipsilateral mutlifocal breast cancer (MFBC)? Breast 26, 149-150 (2016).

50. Winters ZE, Bernaudo L. Evaluating the current evidence to support therapeutic mammoplasty or breast-conserving surgery as an alternative to mastectomy in the treatment of multifocal and multicentric breast cancers. Gland. Surg. 7(6), 525-535 (2018).

51. Rosenkranz KM, Ballman K, McCall $\mathrm{L}$ et al. The feasibility of breast-conserving surgery for multiple ipsilateral breast cancer: an initial report from ACOSOG Z11102 (Alliance) trial. Ann. Surg. Oncol. 25(10), 2858-2866 (2018).

-. Gives an important signal of the growing scientific scenario that will be enriched by the results of trial in progress: in addition to data from multicentric British MIAMI trial, which will evaluate the safety of oncoplastic procedure (breast conservation surgery associated with mammoplasty) in MSIBC, the final evidences of ACOSOG Z11102, now studying locoregional recurrence following BCT for women with MSIBC, as described in this report.

52. Coates AS, Winer EP, Goldhirsch A et al. Tailoring therapies - improving the management of early breast cancer: St Gallen International Expert Consensus on the primary therapy of early breast cancer 2015. Ann. Oncol. 26(8), 1533-1546

53. Goldhirsch A, Winer EP, Coates AS et al. Personalizing the treatment of women with early breast cancer: highlights of the St Gallen International Expert Consensus on the primary therapy of early breast cancer 2013. Ann. Oncol. 24(9), 2206-2223 (2013).

54. Morrow M, Strom EA, Bassett LW et al. Standard for breast conservation therapy in the management of invasive breast carcinoma. $C A$ Cancer J. Clin. 52(5), 277-300 (2002).

55. Galimberti V, Taffurelli M, Leonardi MC et al. Surgical resection margins after breast-conserving surgery: senonetwork recommendations. Tumori. 16(3), 284-289 (2016).

56. Veronesi U, Banfi A, Saccozzi R et al. Conservative treatment of breast cancer. A trial in progress at the Cancer Institute of Milan. Cancer 39(Suppl. 6), 2822-2826 (1977).

57. Mariani L, Salvadori B, Marubini E et al. Ten year results of a randomised trial comparing two conservative treatment strategies for small size breast cancer. Eur. J. Cancer 34(8), 1156-1162 (1998).

58. Fisher B, Redmond C, Poisson R et al. Eight-year results of a randomized clinical trial comparing total mastectomy and lumpectomy with or without irradiation in the treatment of breast cancer. N. Engl. J. Med.320(13), 822-828 (1989).

59. Asgeirsson KS, Rasheed T, McCulley SJ, MacMillan RD. Oncological and cosmetic outcomes of oncoplastic breast conserving surgery. Eur. J. Surg. Oncol. 31(8), 817-823 (2005).

60. Clough KB, Kroll SS, Audretsch W. An approach to the repair of partial mastectomy defects. Plast. Reconstr. Surg. 104(2), 409-420 (1999).

61. Clough KB, Kaufman GJ, Nos C et al. Improving breast cancer surgery: a classification and quadrant per quadrant atlas for oncoplastic surgery. Ann. Surg. Oncol. 17(5), 1375-1391

62. Santos G, Urban C, Edelweiss MI et al. Long-term comparison of aesthetical outcomes after oncoplastic surgery and lumpectomy in breast cancer patients. Ann. Surg. Oncol. 22(8), 2500-2508 (2015).

63. Clough KB, Lewis JS, Couturaud B et al. Oncoplastic techniques allow extensive resections for breast-conserving therapy of breast carcinomas. Ann. Surg. 237(1), 26-34 (2003).

64. Kaur N, Petit JY, Rietjens M et al. Comparative study of surgical margins in oncoplastic surgery and quadrantectomy in breast cancer. Ann. Surg. Oncol. 12(7), 539-545 (2005).

65. Bogusevicius A, Cepuliene D, Sepetauskiene E. The integrated evaluation of the results of oncoplastic surgery for locally advanced breast cancer. Breast J. 20(1), 53-60 (2014).

66. Petit JY, Rietjens M, Contesso G et al. Contralateral mastoplasty for breast reconstruction: a good opportunity for glandular exploration and occult carcinomas diagnosis. Ann. Surg. Oncol. 4(6), 511-515 (1997).

67. Khafagy M, Fakhr I, Hamed A et al. Pedicled dermoglandular flap reconstruction following breast conserving surgery. J. Egypt. Natl. Canc. Inst. 24(2), 91-96 (2012).

68. De Lorenzi F, Hubner G, Rotmensz N et al. Oncological results of oncoplastic breast-conserving surgery: long term follow-up of a large series at a single institution: a matched-cohort analysis. Eur. J Surg. Oncol.. 42(1), 71-77 (2016).

69. Donovan CA, Harit AP, Chung A et al. Oncological and surgical outcomes after nipple-sparing mastectomy: do incisions matter? Ann. Surg. Oncol. 23(10), 3226-3231 (2016).

70. Gunnarsson GL, Bille C, Reitsma LC et al. Prophylactic nipple-sparing mastectomy and direct-to-implant reconstruction of the large and ptotic breast. Plast. Reconstr. Surg. 140(3), 449-454 (2017).

71. Toesca A, Peradze N, Galimberti V et al. Robotic nipple-sparing mastectomy and immediate breast reconstruction with implant. Ann. Surg. 266, e28-e30 (2017).

72. Sarfati B, Honart JF, Leymarie N et al. Robotic da Vinci Xi-assisted nipple-sparing mastectomy: first clinical report. Breast J. 24(3), 373-376 (2017). 
73. Corso G, De Lorenzi F, Vicini E et al. Nipple-sparing mastectomy with different approaches: surgical incisions, complications, and cosmetic results. Preliminary results of 100 consecutive patients at a single center. J Plast. Reconstr. Aesthetic Surg. 71(12), 1751-1760 (2018).

74. Galimberti V, Cole BF, Viale G et al. Axillary dissection versus no axillary dissection in patients with breast cancer and sentinel-node micrometastases (IBCSG 23-01): 10-year follow-up of a randomised, controlled Phase 3 trial. Lancet Oncol. 19(10), 1385-1393 (2018).

75. Veronesi P, De Lorenzi F, Ballardini B et al. Immediate breast reconstruction after mastectomy. Breast 20(Suppl. 3), S104-S107 (2011).

76. Spear SL, Carter ME, Schwarz K. Prophylactic mastectomy: indications, options, and reconstructive alternatives. Plast. Reconstr. Surg. 115(3), 891-909 (2005).

77. Majdak-Paredes EJ, Fatah F. Hereditary breast cancer syndromes and clinical implications. J. Plast. Reconstr. Aesthetic Surg. 62(2), 181-189 (2009).

78. Nava MB, Cortinovis U, Ottolenghi J et al. Skin-reducing mastectomy. Plast. Reconstr. Surg. 118(3), 603-610 (2006).

79. De Lorenzi F, Rietjens $\mathrm{M}$, Soresina $\mathrm{M}$ et al. Immediate breast reconstruction in the elderly: can it be considered an integral step of breast cancer treatment? The experience of the European Institute of Oncology, Milan. J. Plast. Reconstr. Aesthet. Surg. 63(3), 511-515 (2010).

80. Petit JY, Gentilini O, Rotmensz N et al. Oncological results of immediate breast reconstruction: long term follow-up of a large series at a single institution. Breast Cancer Res. Treat. 112(3), 545-549 (2008).

81. Petit JY, Rietjens M, Lohsiriwat V et al. Update on breast reconstruction techniques and indications. World J. Surg. 36(7), 1486-1497 (2012).

82. Garusi $\mathrm{C}$, Lohsiriwat $\mathrm{V}$, Brenelli $\mathrm{F}$ et al. The value of latissimus dorsi flap with implant reconstruction for total mastectomy after conservative breast cancer surgery recurrence. Breast 20(2), 141-144 (2011).

83. Angelos P, Bedrosian I, Euhus DM et al. Contralateral prophylactic mastectomy: challenging considerations for the surgeon. Ann. Surg. Oncol. 22(10), 3208-3212 (2015).

84. Koskenvuo L, Svarvar C, Suominen $\mathrm{S}$ et al. The frequency and outcome of breast cancer risk-reducing surgery in Finnish BRCA1 and BRCA2 mutation carriers. Scand. J. Surg. 103(1), 34-40 (2014).

85. Arver B, Isaksson K, Atterhem H et al. Bilateral prophylactic mastectomy in Swedish women at high risk of breast cancer. Ann. Surg. 253(6), 1147-1154 (2011).

86. Harris LN, Ismaila N, McShane LM et al. Use of biomarkers to guide decisions on adjuvant systemic therapy for women with early-stage invasive breast cancer: American Society of Clinical Oncology Clinical Practice guideline. J. Clin. Oncol. 34(10), 1134-1150 (2016).

87. Early Breast Cancer Trialists' Collaborative Group (BCSCG). Effects of chemotherapy and hormonal therapy for early breast cancer on recurrence and 15-year survival: an overview of the randomised trials. Lancet 365(9472), 1687-1717 (2005).

88. Mauri D, Pavlidis N, Ioannidis JPA. Neoadjuvant versus adjuvant systemic treatment in breast cancer: a meta-analysis. J. Natl. Cancer Inst. 97(3), 188-194 (2005).

89. Thompson AM, Moulder-Thompson SL. Neoadjuvant treatment of breast cancer. Ann. Oncol. 23(Suppl. 10), x231-x236 (2012).

90. Prowell TM, Pazdur R. Pathological complete response and accelerated drug approval in early breast cancer. N. Engl. J. Med. 366(26), 2438-2441 (2012).

91. Fisher B, Anderson S, Bryant J et al. Twenty-year follow-up of a randomized trial comparing total mastectomy, lumpectomy, and lumpectomy plus irradiation for the treatment of invasive breast cancer. N. Engl. J. Med. 347(16), 1233-1241 (2002).

92. Clarke M, Collins R, Darby S et al. Effects of radiotherapy and of differences in the extent of surgery for early breast cancer on local recurrence and 15-year survival: an overview of the randomised trials. Lancet 366(9503), 2087-2106 (2005).

93. Poortmans P, Bartelink H, Horiot JC et al. The influence of the boost technique on local control in breast conserving treatment in the EORTC "boost versus no boost" randomised trial. Radiother. Oncol. 72(1), 25-33 (2004).

94. Veronesi U, Marubini E, Mariani L et al. Radiotherapy after breast-conserving surgery in small breast carcinoma: long-term results of a randomized trial. Ann. Oncol. 12(7), 997-1003 (2001).

95. Bartelink H, Horiot JC, Poortmans PM et al. Impact of a higher radiation dose on local control and survival in breast-conserving therapy of early breast cancer: 10-year results of the randomized boost versus no boost EORTC 22881-10882 trial. J. Clin. Oncol. 25(22), 3259-3265 (2007).

96. Patani N, Carpenter R. Oncological and aesthetic considerations of conservational surgery for multifocal/multicentric breast cancer. Breast J. 16(3), 222-232 (2010).

97. Vrieling C, van Werkhoven E, Maingon P et al. Prognostic factors for local control in breast cancer after long-term follow-up in the EORTC boost vs no boost trial. JAMA Oncol. 3(1), 42-48 (2017).

98. Bartelink H, Maingon P, Poortmans P et al. Whole-breast irradiation with or without a boost for patients treated with breast-conserving surgery for early breast cancer: 20-year follow-up of a randomised phase 3 trial. Lancet Oncol. 16(1), 47-56 (2015).

99. Kurtz JM, Jacquemier J, Amalric R et al. Breast-conserving therapy for macroscopically multiple cancers. Ann. Surg. 212(1), 38-44 (1990). 
100. Wilson LD, Beinfield M, McKhann CF, Haffty BG. Conservative surgery and radiation in the treatment of synchronous ipsilateral breast cancers. Cancer 72(1), 137-142 (1993).

101. Chung AP, Huynhm K, Kidner T et al. Comparison of outcomes of breast conserving therapy in multifocal and unifocal invasive breast cancer. J. Am. Coll. Surg. 215(1), 137-146 (2012).

102. Shaikh T, Tam TY, Li T et al. Multifocal and multicentric breast cancer is associated with increased local recurrence regardless of surgery type. Breast J. 21(2), 121-126 (2015).

103. Okumura S, Mitsumori M, Yamauchi C et al. Feasibility of breast-conserving therapy for macroscopically multiple ipsilateral breast cancer. Int. J. Radiat. Oncol. Biol. Phys. 59(1), 146-151 (2004).

104. Lim W, Park EH, Choi SL et al. Breast conserving surgery for multifocal breast cancer. Ann. Surg. 249(1), 87-90 (2009).

105. Wolters R, Wöckel A, Janni W et al. Comparing the outcome between multicentric and multifocal breast cancer: what is the impact on survival, and is there a role for guideline-adherent adjuvant therapy? A retrospective multicenter cohort study of 8,935 patients. Breast Cancer Res. Treat. 142(1), 579-590 (2013).

106. Lehman M, Hickey B. The less than whole breast radiotherapy approach. Breast 19(3), 180-187 (2010).

107. Shah C, Vicini F, Wazer DE et al. The American Brachytherapy Society consensus statement for accelerated partial breast irradiation. Brachytherapy 12(4), 267-277 (2013).

108. Correa C, Harris EE, Leonardi MC et al. Accelerated partial breast irradiation: executive summary for the update of an ASTRO evidence-based consensus statement. Pract. Radiat. Oncol. 7(2), 73-79 (2017).

109. Polgár C, Van Limbergen E, Pötter R et al. Patient selection for accelerated partial-breast irradiation (APBI) after breast-conserving surgery: recommendations of the Groupe Européen de Curiethérapie-European Society for Therapeutic Radiology and Oncology (GEC-ESTRO) breast cancer working group based on clinical evidence (2009). Radiother. Oncol. 94(3), 264-273 (2010).

110. Leonardi MC, Maisonneuve P, Mastropasqua MG et al. How do the ASTRO consensus statement guidelines for the application of accelerated partial breast irradiation fit intraoperative radiotherapy? A retrospective analysis of patients treated at the European Institute of Oncology. Int. J. Radiat. Oncol. Biol. Phys. 83(3), 806-813 (2012).

111. Leonardi MC, Maisonneuve P, Mastropasqua MG et al. Accelerated partial breast irradiation with intraoperative electrons: using GEC-ESTRO recommendations as guidance for patient selection. Radiother. Oncol. 106(1), 21-27 (2013).

112. Tendulkar RD, Chellman-Jeffers M, Rybicki LA et al. Preoperative breast magnetic resonance imaging in early breast cancer: implications for partial breast irradiation. Cancer 115(8), 1621-1630 (2009).

113. McHaffie DR, Patel RR, Adkison JB et al. Outcomes after accelerated partial breast irradiation in patients with ASTRO consensus statement cautionary features. Int. J. Radiat. Oncol. Biol. Phys. 81(1), 46-51 (2011).

114. Magee B, Swindell R, Harris M, Banerjee SS. Prognostic factors for breast recurrence after conservative breast surgery and radiotherapy: results from a randomised trial. Radiother. Oncol. 39(3), 223-227 (1996).

115. Leonardi MC, Ricotti R, Dicuonzo S et al. From technological advances to biological understanding: the main steps toward high-precision RT in breast cancer. Breast 29, 213-222 (2016).

116. Strnad V, Hildebrandt G, Pötter R et al. Accelerated partial breast irradiation: 5-year results of the german-austrian multicenter Phase II trial using interstitial multicatheter brachytherapy alone after breast-conserving surgery. Int. J. Radiat. Oncol. 80(1), 17-24 (2011).

117. Leonardi MC, Maisonneuve P, Mastropasqua MG et al. Comparison of treatment outcome between invasive lobular and ductal carcinomas in patients receiving partial breast irradiation with intraoperative electrons. Int. J. Radiat. Oncol. Biol. Phys. 99(1), 173-181 (2017).

118. Sardanelli F, Boetes C, Borisch B et al. Magnetic resonance imaging of the breast: recommendations from the EUSOMA working group. Eur. J. Cancer 46(8), 1296-1316 (2010).

119. Fortunato L, Mascaro A, Poccia I et al. Lobular breast cancer: same survival and local control compared with ductal cancer, but should both be treated the same way? Analysis of an institutional database over a 10-year period. Ann. Surg. Oncol. 19(4), 1107-1114 (2012).

120. Girardi V, Carbognin G, Camera L et al. Multifocal, multicentric and contralateral breast cancers: breast MR imaging in the preoperative evaluation of patients with newly diagnosed breast cancer. Radiol. Med. 116(8), 1226-1238 (2011).

121. van den Broek N, van der Sangen MJC, van de Poll-Franse LV et al. Margin status and the risk of local recurrence after breast-conserving treatment of lobular breast cancer. Breast Cancer Res. Treat. 105(1), 63-68 (2007).

122. Mai KT, Yazdi HM, Isotalo PA. Resection margin status in lumpectomy specimens of infiltrating lobular carcinoma. Breast Cancer Res. Treat. 60(1), 29-33 (2000).

123. Jolly S, Kestin LL, Goldstein NS, Vicini FA. The impact of lobular carcinoma in situ in association with invasive breast cancer on the rate of local recurrence in patients with early-stage breast cancer treated with breast-conserving therapy. Int. J. Radiat. Oncol. 66(2), 365-371 (2006).

124. Sastre-Garau X, Jouve M, Asselainm B et al. Infiltrating lobular carcinoma of the breast. Clinicopathologic analysis of 975 cases with reference to data on conservative therapy and metastatic patterns. Cancer 77(1), 113-120 (1996). 
125. Pedersen L, Gunnarsdottir K, Rasmussen B et al. The prognostic influence of multifocality in breast cancer patients. Breast 13(3), 188-193 (2004).

126. Andea AA, Wallis T, Newman LA et al. Pathologic analysis of tumor size and lymph node status in multifocal/multicentric breast carcinoma. Cancer 94(5), 1383-1390 (2002).

127. Lynch SP, Lei X, Hsu L et al. Breast cancer multifocality and multicentricity and locoregional recurrence. Oncologist 18(11), 1167-1173 (2013).

128. Poortmans P. Postmastectomy radiation in breast cancer with one to three involved lymph nodes: ending the debate. Lancet 383(9935), 2104-2106 (2014).

129. Katz A, Strom EA, Buchholz TA et al. Locoregional recurrence patterns after mastectomy and doxorubicin-based chemotherapy: implications for postoperative irradiation. J. Clin. Oncol. 18(15), 2817-2827 (2000).

130. Linshaw D, Tonneson J, Rosenkranz K. Surgical therapy for women with multiple synchronous ipsilateral breast cancer (MIBC): current evidence to guide clinical practice. Curr. Breast Cancer Rep. 11(2), 67-73 (2019). 